\title{
Placenta percreta: a successful conservative outcome
}

\section{Nigamananda Mishra, Devika Desai*, Santoshi Prabhu, Vaishali Jadhav}

Department of Obstetrics and Gynecology, Bhabha Atomic Research Centre and Hospital, Mumbai, Maharashtra, India

Received: 01 June 2018

Accepted: 05 July 2018

\section{*Correspondence:}

Dr. Devika Desai,

E-mail: devikadesai1090@gmail.com

Copyright: () the author(s), publisher and licensee Medip Academy. This is an open-access article distributed under the terms of the Creative Commons Attribution Non-Commercial License, which permits unrestricted non-commercial use, distribution, and reproduction in any medium, provided the original work is properly cited.

\begin{abstract}
Placental adherent syndromes have been known to us since antiquity. These are very much common in the present era due to rising incidence of surgical evacuation of pregnancy, caesarean sections and hysterotomy. Thought to be due to abnormal trophoblastic invasion at the endo-myometrial junction along with vasculature leading to varying degrees of invasion and adherence, lastly including the pelvic organs. Morbidity and mortality associated with these have been an obstetrician's nightmare and thus a good learning curve. Hence, knowing appropriate case selection and management in terms of early diagnosis, mode of delivery, dealing with obstetric emergencies and appropriate counseling has become the need of the hour. The focus being, conservative management and best perinatal outcome with least maternal morbidity
\end{abstract}

Keywords: Placenta percreta, Placental adherent syndromes, Placenta preavia

\section{INTRODUCTION}

Placenta accreta, a general term describes a condition wherein part or entire placenta invades and is not separable from uterine wall. Placenta increta involves and invades myometrium only. Placenta percreta involves invasion through myometrium upto the serosa with or without involvement of adjacent organs. ${ }^{1}$ Presently, the incidence of placenta accreta is 1 in 2,500 antenatal patients and occurs due to abnormal placental vasculature development.

These have been very common in patients with history of previous caesarean deliveries, curettage, abortions and placenta praevia. The mortality associated risk is about 7 $\%$ and the surgery related morbidities which include need for active postpartum haemorrhage management, dealing with extensive bowel and bladder involvement and injuries and most importantly emergency caesarean hysterectomies ranged from 5-15\%. ${ }^{2}$ Important modalities of diagnosis are ultrasound -2D, 3D with color doppler-findings suggestive are placental-uterine interface loss, thinning of myometrium less than $1 \mathrm{~mm}$, placental lacunae and abnormal uterine bladder interface. MRI may be done for confirmation of placental adherent syndromes. ${ }^{3}$ Thus, need for a good preoperative workup and more conservative approach to decrease morbidity and mortality associated with it. Here, we describe a case of placenta percreta successfully managed conservatively.

\section{CASE REPORT}

A 31 years old married since 9 years, gravida 2 para1 living 1 previous caesarean delivery with gestational hypothyroidism on tab Eltroxin 12.5 micrograms was registered in early pregnancy. Previous lscs done in view of non-progress of labor at term 6 years back. Patient got admitted at 30 weeks in view of usg-s/o complete placenta preavia covering the os. She was asymptomatic. Antenatal investigations-within normal limit, $\mathrm{Hb}-12.5$ gm\%, blood group-A positive. Previous scans - nuchal 
translucency and anomaly scan showed no abnormality. Two doses of injection Betamethasone was given. MRI was done in view of severe abdominal pain and was s/o.low lying placenta completely covering os -grade 4 , loss of T2 isointense myometrial signal predominantly along left lateral wall of lower uterine segment suggestive of placenta reaching upto the serosa consistent with placenta percreta (Figure 1). Patient was given complete bed rest with fetal monitoring.

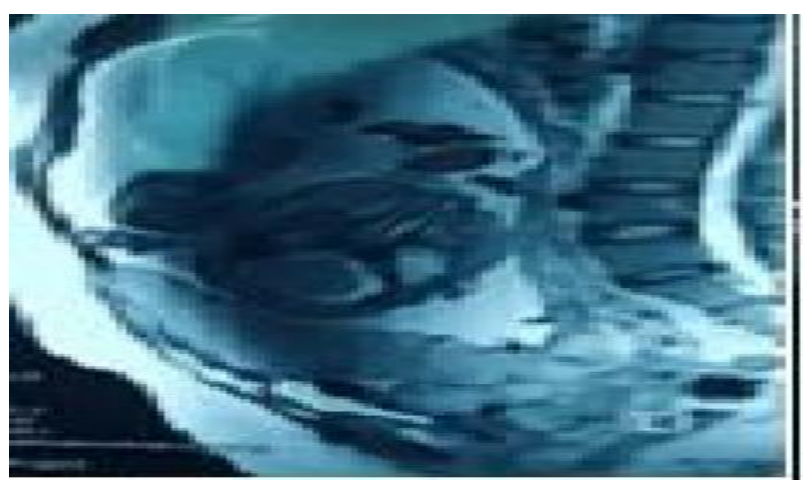

Figure 1: Preoperative MRI.

Patient underwent emergency caesarean section at 34 weeks on 21/9/2017 in view of per vaginal bleeding. Pfannensteil incision given and abdomen opened in layers. Intraoperative findings-The previous uterine scar had undergone dehiscence with only amniotic membrane visible with lot of vascular prominences.

Lower segment was bosselated with infiltration of placenta till the serosa of the uterus being very close to the bladder with vascular prominences over lower uterine segment. Bladder dissection was difficult and caused lot of bleeding (Figure 2).

Incision was given over dehiscense area and baby delivered by breech extraction a female child of weight $2.3 \mathrm{~kg}$. There was central placenta praevia completely covering os, placental separation was not possible as it was completely infiltrating. Uterotonics were given and uterine closure done in single layer with placenta in situ (Figure 3).

There was no immediate postpartum hemorrhage. Abdomen closed in layers. Post operatively patient was stable until 7 days, when 2 packed cell volumes were transfused in view of drop in hemoglobin by $2 \mathrm{gm} \%$.

Injectable antibiotics were given for 7 days with injection methotrexate $1 \mathrm{mg} / \mathrm{kg}$ multidose regimen -total 4 doses with alternate day injection leucovorin. Repeat usg done on day 8 s/o-abdomen, kub- normal study. Usg pelvisuterus bulky, placental tissue in lower uterine segment covering the os with thin rim of tissue in retroplacental region, no evidence of collection in pouch of douglas.

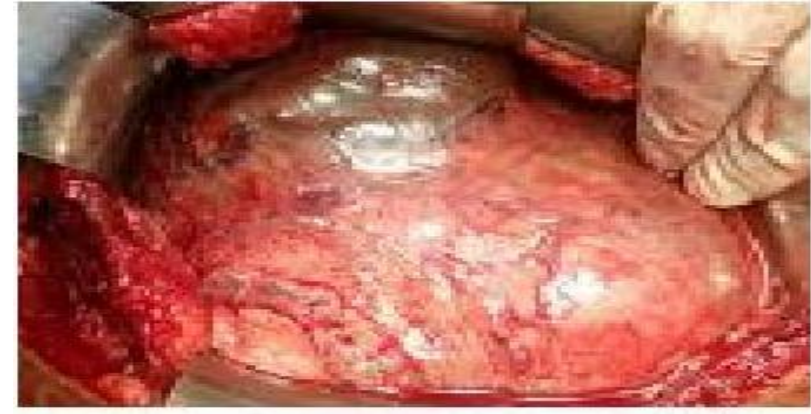

Figure 2: Intraoperative view.

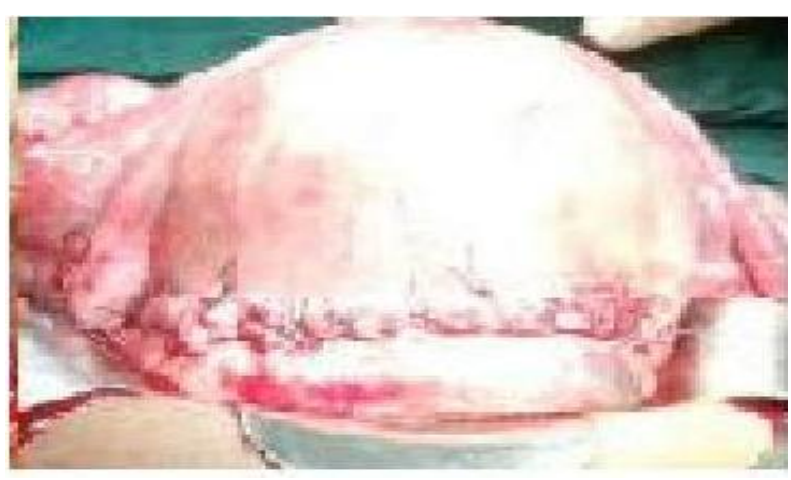

Figure 3: Post uterine closure.

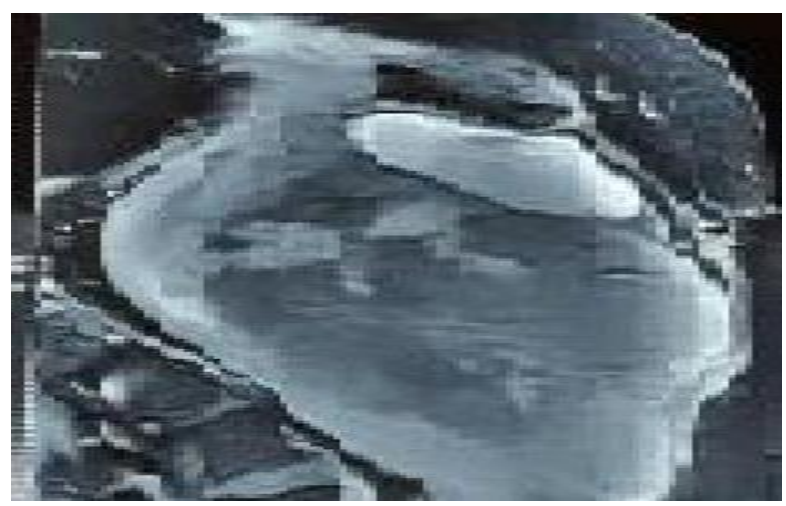

Figure 4: Postoperative MRI.

Patient was admitted around $100^{\text {th }}$ day post-surgery in view of fever spikes and altered brownish discharge. Injectable antibiotics ceftriaxone and metronidazole was given for 7 days and WBC count monitored. Repeat MRI-s/o retained placenta in left antero-lateral wall of uterus reaching both anterior and left lateral walls of uterus not infiltrating bladder or bowel (Figure 4).

Decision was taken for evacuation of retained placenta. Usg guided dilatation and evacuation of retained placenta with small bits of placental tissue adherent to the anterior wall left behind. Patient tolerated procedure well and was symptomatically better. She was given antibiotics for 7 days. Serial HCG levels as follows. 
Table 1: Serial HCG levels.

\begin{tabular}{|llllllll|}
\hline Date & $4 / 10 / 2017$ & $10 / 10 / 2017$ & $18 / 10 / 2017$ & $8 / 11 / 2017$ & $12 / 12 / 2017$ & $22 / 12 / 2017$ & $13 / 1 / 2018$ \\
\hline Day & 15 & 21 & 28 & 49 & 83 & 93 & 115 \\
\hline HCG & 4924 & 2639 & 986 & 253 & 106 & 39 & 1.2 \\
\hline
\end{tabular}

Patient got her first menstrual period one-month post procedure-normal flow for 3 days. Repeat scan suggestive of $-3 \mathrm{~cm}$ placental tissue adherent on anterior wall with endometrial thickness of $10 \mathrm{~mm}$. Patient is asymptomatic at present.

\section{DISCUSSION}

Placental adherent syndromes have become challenging in today's time as regards more demand for conservative surgeries and need for fertility preservation. American society recommends caesarean hysterectomy as the gold standard approach for these cases. Conservative approach requires appropriate case selection, good preoperative work up, willingness for long term follow up, good compliance of the patient with emergency facilities at bay to tackle secondary postpartum hemorrhage, any bowel and bladder injury.

Daney et al in the year 2016 studied placental adherent syndromes over the time period 2007-2014 for which conservative approach was done. He found that out of the 15 patients followed up, $80 \%$ had successful conservative approach, $33 \%$ required uterine artery embolisation in view of post-partum hemorrhage, 4 had sepsis requiring hospitalization. He concluded that conservative approach can be a modality, provided there are good healthcare and compliance of patient. ${ }^{4}$

Sawada et al published a case series in 2016, a case series of conservative approach. It has been beautifully depicted and stressed the need for serial MRI imaging over duration for 5 months at intervals of 1 month to look for prognosis and successful documentation of decreasing size of placental tissue observed. ${ }^{5}$

Legendre et al in 2014 conducted a very informative study wherein he studied the results of hysteroscopic removal of retained placenta after conservative approach among 12 patients. Average size of placenta being$54 \mathrm{~mm}$ on MRI. He concluded complete removal of placenta was possible in all except one which required secondary hysterectomy. Thus, proving hysteroscopic removal of placenta post retained placenta as a safe modality. ${ }^{6}$

A case report published in 2010 on conservative management of placenta percreta which was a case of previous lscs with antenatally diagnosed placenta percreta underwent elective lscs. Placenta was kept in situ, medical management done with multiple doses of methotrexate with second look surgery to remove the retained placenta after confirming no invasion. ${ }^{7}$

Das et al in 2014 has described a case report regarding placenta percreta post lscs with placental retention. Post lscs patient was administered injection methotrexate at HCG value of $1980 \mathrm{mIU} / \mathrm{ml}$, multiple dose regimen. Patient was monitored with serial HCG and usg. Dilatation and evacuation was done at $6^{\text {th }}$ postpartum week with complete removal of placental tissue, thus having a successful conservative approach. ${ }^{8}$

A case report published in 2013 by Smith et al, concludes need for multidisciplinary approach and need for intraoperative ureteral stents for better visualization in case of conservative management of placenta percreta. ${ }^{9}$

28 years old underwent third caesarean section in view of bleeding placenta praevia followed by a laparotomy due to secondary postpartum hemorrhage. Retained placenta was removed with hemostatic sutures being taken, followed by hysteroscopic balloon tuboplasty and laparoscopic tubal adhesiolysis were done at a later date. Thus, conserving the uterus. ${ }^{10}$

\section{CONCLUSION}

Placental adherent syndromes can now be successfully managed conservatively by combination of medical with surgical management provided with good infrastructure, long term follow up and compliance.

\section{Funding: No funding sources \\ Conflict of interest: None declared \\ Ethical approval: Not required}

\section{REFERENCES}

1. Canonico S, Arduini M, Epicoco G, Luzi G, Arena S, Clerici G, et al. Placenta previa percreta: a case report of successful management via conservative surgery. Case reports in obstetrics and gynecology. 2013;2013: 702067.

2. Aggarwal R, Suneja A, Vaid NB, Yadav P, Sharma A, Mishra K. Morbidly adherent placenta: a critical review. J Obstet Gynaecol India. 2012;62(1):57-61.

3. Goh WA, Zalud I. Placenta accreta: diagnosis, management and the molecular biology of the morbidly adherent placenta. J Matern Fetal Neonatal Med. 2016;29(11):1795-800.

4. Marcillac FD, Lecointre L, Guillaume A, Sananes N, Fritz G, Viville B, Boudier E, Nisand I, et al. 
Morbimortality maternal associated with conservative treatment of an abnormally adherent placenta (accreta) diagnosed prenatally. About a continuous series of 15 cases. J Gynecol Obstetr Biol Reprod. 2016;45(8):849-58.

5. Sawada M, Matsuzaki S, Mimura K, Kumasawa K, Endo M, Kimura T. Successful conservative management of placenta percreta: Investigation by serial magnetic resonance imaging of the clinical course and a literature review. J Obstet Gynaecol Res. 2016;42(12):1858-63.

6. Legendre G, Zoulovits FJ, Kinn J, Senthiles L, Fernandez H. Conservative management of placenta accreta: hysteroscopic resection of retained tissues. J Minimally Invasive Gynecol. 2014;21(5):910-3.

7. Çırpan T, Sanhal CY, Yücebilgin S, Özşener S. Conservative management of placenta previa percreta by leaving placental tissue in situ with arterial ligation and adjuvant methotrexate therapy. J Turkish German Gynecol Assoc. 2011;12(2):127.

8. Das SS, Devi LS, Singh LR, Singh R. Conservative management of placenta accreta with injection methotrexate to preserve fertility. J Med Soc. 2014;28(2):125.

9. Smith ZL, Sehgal SS, Van Arsdalen KN, Goldstein IS. Placenta percreta with invasion into the urinary bladder. Urol Case Reports. 2014;2(1):31-2.

10. Caliskan E, Vural B, Turkoz E, Tan O. Conservative surgical management of placenta percreta: two cases with an emphasis on tubal patency. Gynecol Surg. 2005;2(1):29-31.

Cite this article as: Mishra N, Desai D, Prabhu S, Jadhav V. Placenta percreta: a successful conservative outcome. Int J Reprod Contracept Obstet Gynecol 2018;7:3377-80. 